\title{
$\beta$ - but not $\gamma$-secretase proteolysis of APP causes synaptic and memory deficits in a mouse model of dementia
}

\author{
Robert Tamayev ${ }^{1}$, Shuji Matsuda ${ }^{1}$, Luciano D'Adamio ${ }^{1,2^{*}}$ \\ From 2011 International Conference on Molecular Neurodegeneration \\ Shanghai, China. 22-24 September 2011
}

\begin{abstract}
Background
Amyloid deposition of $\mathrm{A} \beta$ peptide characterizes $\mathrm{AD}$. $\mathrm{A} \beta$ derives from sequential cleavage of APP by $\beta$ - and $\gamma$-secretases. Interestingly, mutations in either $A P P$ or the $\gamma$-secretase genes PSEN1/2 cause familial AD (FAD). Mutation of BRI2/ITM $2 b$ causes an AD-like familial dementia (FDD) with amyloid deposits. The FDD plaques contain $A \beta$ and $A D a n$, which derives from processing of mutant BRI2 protein by pro-protein convertases. Since amyloidogenic peptides are believed to cause dementias, transgenic mice carrying mutant $A P P$, $P S E N 1 / 2$ or $B R I 2 / I T M 2 b$ are used to model these dementias, as over-expression is necessary to reproduce amyloidosis. However, over-expression of mutant genes might produce harmful effects unrelated to dementias and lead to erroneous information concerning pathogenesis and therapy of human diseases. The clinical failures of compounds efficacious in transgenic models support this hypothesis.
\end{abstract}

\section{Methods}

To avoid artifacts of over-expression, we generated a knock-in mouse model of FDD (FDD $\left.{ }_{\mathrm{KI}}\right)$ that, like FDD patients, is heterozygous for one mutated FDD allele of $B R I 2 / I T M 2 b$. $\mathrm{FDD}_{\mathrm{KI}}$ mice develop progressive synaptic and memory deficits due to loss of Bri2 function, with no amyloidosis and tauopathy. BRI2 binds APP and inhibits APP processing; owing to the loss of BRI2, APP processing is increased in FDD. Remarkably, memory deficits of $\mathrm{FDD}_{\mathrm{KI}}$ mice require $\mathrm{APP}$, providing genetic evidence that
APP and BRI2 functionally interact, and that APP mediates FDD neuropathology.

\section{Results}

APP processing is genetically linked to AD pathogenesis, which is consistent with a common mechanism involving toxic APP metabolites in both dementias and prompts the question whether blocking APP processing ameliorates FDD. Here we show that either a BRI2-derived peptide that, like BRI2, binds APP and blocks its cleavage by $\beta$-secretase, or a $\beta$-secretase inhibitor, rescues synaptic and memory deficits of $\mathrm{FDD}_{\mathrm{KI}}$ mice. $\beta$-cleavage of APP yields two metabolites, amino terminal soluble APP $\beta$ (sAPP $\beta$ ) and $\beta$-carboxyl terminal fragment ( $\beta$-CTF). Further processing of $\beta$-CTF by $\gamma$-secretase cleavage releases amyloid- $\beta$, which is reputed to be central to AD pathophysiology. Intriguingly however, inhibition of $\gamma$-secretase did not ameliorate the synaptic and memory deficits of FDD mice.

\section{Conclusions}

This result demonstrates that APP proteolysis triggers FDD, and establishes the importance of $\beta$-processing of APP for dementia to occur. Moreover, the data indicated instead that SAPP $\beta$ and/or $\beta$-CTF, rather than amyloid- $\beta$, are the toxic species causing dementia. This suggests that reducing $\beta$-cleavage of APP is an appropriate therapeutic approach to treating human dementias, while discouraging targeting $\gamma$-secretase cleavage of APP and/or amyloid- $\beta$. The recurring failures of anti-amyloid- $\beta$ therapies in humans are consistent with this hypothesis.

\footnotetext{
* Correspondence: luciano.dadamio@einstein.yu.edu

'Department of Microbiology \& Immunology, Albert Einstein College of

Medicine, Bronx, New York, USA

Full list of author information is available at the end of the article
} 


\section{Author details}

'Department of Microbiology \& Immunology, Albert Einstein College of Medicine, Bronx, New York, USA. ${ }^{2}$ Institute of Cellular Biology and Neurobiology, National Council of Research of Rome, Italy.

Published: 7 February 2012

doi:10.1186/1750-1326-7-S1-L9

Cite this article as: Tamayev et al:: $\beta$ - but not $\gamma$-secretase proteolysis of APP causes synaptic and memory deficits in a mouse model of dementia. Molecular Neurodegeneration 2012 7(Suppl 1):L9.

Submit your next manuscript to BioMed Central and take full advantage of:

- Convenient online submission

- Thorough peer review

- No space constraints or color figure charges

- Immediate publication on acceptance

- Inclusion in PubMed, CAS, Scopus and Google Scholar

- Research which is freely available for redistribution

Submit your manuscript at www.biomedcentral.com/submit 